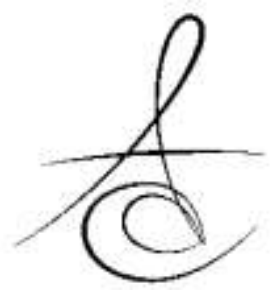

\section{DİKEY YÖNDE DEFEKTİ OLAN HASTALARDA ANDREWS KÖPRÜ SİSTEMİ İLE PROTETİK REHABİLITASYON: İKİ OLGU SUNUMU ${ }^{\neq}$}

\section{PROSTHETIC REHABILITATION OF THE PATIENTS WITH VERTICAL DEFECT WITH ANDREWS BRIDGE SYSTEM: TWO CASE REPORTS ${ }^{\ddagger}$}

\author{
Arş. Gör. Dt. Zahide AYDIN* \\ Prof. Dr. Nuran YANIKOĞLU \\ Arş. Gör. Dt. Mehmet Fatih ÖZMEN*
}

Zahide Aydın: ORCID ID: 0000-0003-2666-3139

Nuran Yanıkoğlu: ORCID ID: 0000-0001-7677-1248

Mehmet Fatih Özmen: ORCID ID: 0000-0001-8613-551X

öz

Dikey kemik kaybı olan hastalar, protetik rehabilitasyon için büyük zorluk yaşamaktadır. Bu şekilde olan vakalarda sabit dental protezler, destek dişlerin yetersizliğinden ve kayıp yumuşak dokunun telafi gerekliliğinden dolayı tercih edilemeyebilir. Hareketli protezler palatal ve lingual kaplama nedeniyle konforsuz alan oluşturur. İmplant destekli protezler geniş kemik kayıplarında sorgulanabilir prognoza sahiptir. Andrews köprü sistemi sabit ve hareketli sistemlerin kombinasyonudur ve geniş kret defektlerinde hareketli parçayla birlikte doğal dişlerin destek olarak kullanıldığı sabit kısımdan oluşur.

1.Vaka: Geniş yumuşak ve sert doku kaybıyla ilişkili mandibular premolar bölgede dişsiz alan şikayetiyle Atatürk Üniversitesi Diş Hekimliği Fakültesi'ne başvuran 37 yaşındaki erkek hastanın destek olarak seçilen dişleri tam kuron restorasyon prensiplerine bağlı olarak prepare edildi.

2.Vaka: 2 sene önce trafik kazası geçiren ve bu kaza sonucu maksillada oluşan kırıkları miniplaklarla fikse edilmiş 27 yaşındaki erkek hasta kliniğimize başvurdu. Hastanın maksiller sağ santral kökü çekildi. Hastanın klinik muayenesinde maksilla anterior bölgede dikey ve yatay sert ve yumuşak doku kayıpları gözlendi.

Her iki vakada da aynı işlemler yapıldı: Silikon ölçü maddesiyle alınan ölçüler laboratuvara gönderildi. Metal alt yapıların kontrolünden sonra, diş ve dişeti rengine uygun olacak şekilde hazırlanan final restorasyonlar hastaya başarılı şekilde uygulandı. Hastaların 3, 6 ve 12 aylık kontrollerinde estetik ve fonksiyonel olarak protezlerin başarılı olduğu görüldü.

Andrews köprü sistemi ile özellikle anteriorda geniş kemik ve yumuşak doku kaybı olan genç hastalardaki protetik rehabilitasyonda, estetik ve fonksiyonel olarak memnun edici sonuçlar elde edilebilir. Andrews köprü sistemi, dikkatli teşhis ve planlama yapıldığında iyi bir prognoz sağlar.

Anahtar kelimeler: Andrews Köprü, Sabit hareketli protez, Geniş kemik kaybı

\title{
ABSTRACT
}

Patients with vertical bone loss have great difficulty for prosthetic rehabilitation. In such cases, fixed dental prostheses may not be preferred due to the lack of support teeth and the need to compensate for missing soft tissue. The removable prostheses forms an uncomfortable area due to palatal and lingual covering. Implant-supported prosheses have a questionable prognosis in large bone loss. The Andrews bridge system is a combination of fixed and removable systems and in the case of wide crest defects, it consists of a fixed part where the natural teeth are used as a support together with the removing part.

Case 1: The teeth of a 37-year-old male patient who applied to the Atatürk University Faculty of Dentistry with the complaint of toothless area in the mandibular premolar region associated with extensive soft and hard tissue loss were prepared according to the principles of full crown restoration.

Case 2: A 27-year-old male patient who had a traffic accident 2 years ago and who had fractures in the maxilla was fixed with miniplaks applied to our clinic. The maxillary right central root of the patient was extracted. In the clinical examination, vertical and horizontal hard and soft tissue losses were observed in the anterior region of the maxilla. The same procedure was performed in both cases: Silicon-based impression was sent to the laboratory. After the control of the metal infrastructures, the final restorations prepared according to the tooth and gum color were successfully applied to the patient. In the 3, 6 and 12 month follow-up examinations of the patients were successful.

With the Andrews bridge system, aesthetic and functional satisfactory results can be obtained in prosthetic rehabilitation of young patients, especially those with large anterior bone and soft tissue loss. Andrew's bridge system provides a good prognosis if diagnosed and planned carefully.

Key Words: Andrews Bridge, Fixed-removable Denture, Extensive Bone Loss

* Atatürk Üniversitesi Diș Hekimliği Fakültesi Protetik Diș Tedavisi Anabilim dalı, Erzurum

F Uluslararası Koruyucu Diş Hekimliği Kongresi, 'nde Poster Olarak Sunulmuştur. 5-8 Mart-2018 Palandöken Kayak Merkezi-Erzurum/Türkiye

Kaynakça Bilgisi: Aydın Z, Yanıkoğlu N, Özmen MF. Dikey Yönde Defekti Olan Hastalarda Andrews Köprü Sistemi ile Protetik Rehabilitasyon: İki Olgu Sunumu.. Atatürk Üniv Diş Hek Fak Derg 2020; 30: 306-311.

Citation Information: Aydin Z, Yanikoglu N, Ozmen MF. Prosthetic Rehabilitation of the Patients With Vertical Defect With Andrews Bridge System: Two Case Reports. J Dent Fac Atatürk Uni 2020; 30: 306-311. 


\section{GİRİş}

Diş hekimliğinin protetik diş tedavisi bölümü, eksik olan dişlerin ve komşu dokuların suni materyallerle değiştirilmesi ve hastanın oral işlevlerinin, konforunun, görünüşünün ve sağlığının restorasyonunu ve bakımını içerir. ${ }^{1}$ Çoğu hasta, estetik nedenlerden ve kullanım rahatlığından dolayı öncelikli olarak sabit protez uygulamasını tercih etse de, periodontal dokuların yetersizliği ve dişsiz alanın uzunluğu nedeniyle uygun tedavi olarak uygulanamayabilmektedir. Defektle birlikte birkaç diş eksikliği bulunan dişsiz kret bölgelerinde, palatal ekstansiyonuna bağlı rahatsızlık nedeniyle hareketli parsiyel protezin başarısız olduğu vakalarda, sabit protezin başarısız olduğu uzun dişsiz alanlarda ve yarık damak hastalarında Andrews köprü sistemi tercih edilebilir. ${ }^{2}$

Andrews geniş doku defektlerinin tedavisinde barlı protez kullanımın 1965 yılından beri uygulamaktadır. ${ }^{5}$ Elde edilen bar, çekme ve germe kuvvetlerine dayanıklı bir materyalden elde edildiğinde ince olarak hazırlanabilmektedir. Bu hibrid protez, estetik sabit protezin ve hareketli bir protezin rehabilitasyonunun hedeflerine benzer şekilde destek, stabilite ve tutuculuk özellikleri sergiler. ${ }^{6}$ Öte yandan, hassas ataşmanlar, aralıklı dikey masaj yoluyla altta yatan yumuşak dokuya daha iyi destek ve stimülasyon sağlar. ${ }^{7}$

Bu çalışmanın amacı, geniş doku defektli çoklu diş eksikliği olan 2 hastada başarılı şekilde uygulanan Andrews köprü sistemi ile protetik rehabilitasyonunun nasıl yapıldığını anlatmaktır.

\section{VAKA 1}

Atatürk Üniversitesi Diş Hekimliği Fakültesi Protetik Diş Tedavisi kliniğine başvuran 37 yaşındaki erkek hastanın mevcut kısmi dişsizliğinin tedavisi için klinik ve radyolojik muayenesi yapıldı (Şekil 1-3). Hastadan gerekli prosedürlerin ayrıntılı anlatıldığı, çalışmada yer almayı kabul ettiği gönüllü onam formu alındı.

Sol alt mandibular bölgede köprü sökümü sonrası sol alt kanin dişinin çekimine karar verildi. Mandibular sol ikinci küçük azı diş daha önceden prepare edilmişti.

Sol alt mandibular bölgedeki geniş defektli uzun dişsiz boşluğa "Andrews Köprü Sistemi" yapılmasına karar verildi. Sol mandibular bölgede santral, lateral ve ikinci küçük azı dişi Andrews köprü sisteminin sabit komponentinin destek dişleri olarak belirlenerek preperasyonları gerçekleştirildi (Şekil 4).

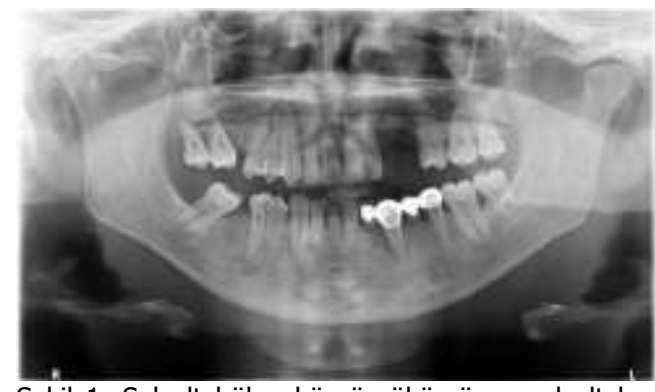

Şekil 1. Sol alt bölge köprü sökümü ve sol alt kanin dişinin çekim öncesi radyografisi

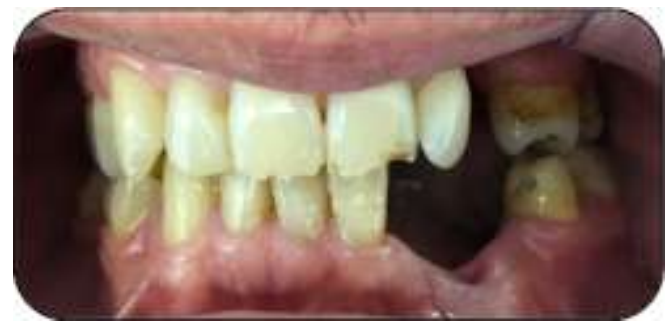

Şekil 2. İşlem öncesi kapanış fotoğrafı

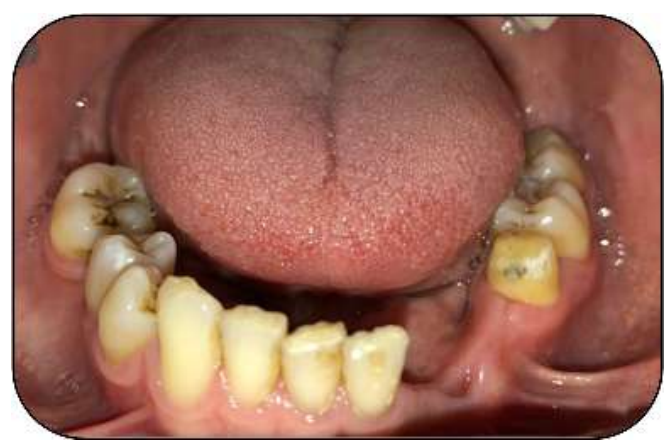

Şekil 3. Geniş doku kayıbı ile beraber çoklu diş eksikliği görülen sol alt mandibular bölge

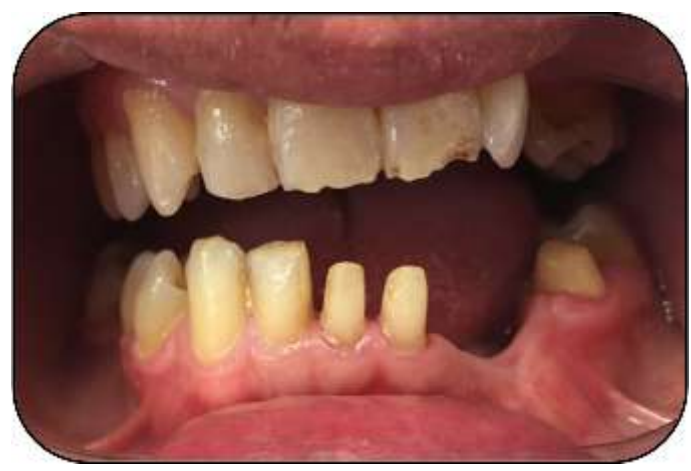

Şekil 4. Sabit komponente destek diş olarak seçilen sol mandibular bölgede santral, lateral ve ikinci küçük azı dişi preparasyonu 
Elastomerik ölçü maddesi (ELITE HD PUTTY; Zhermack, Rovigo, Italy) kullanılarak ölçü alındı. Sabit restorasyonun yapılması için laboratuvarda alçı model elde edildi. Krom Kobalt materyalinden döküm yöntemiyle sabit kısmın alt yapısı hazırlandı, ağızda prova edildi, metal alt yapı üzerine felspatik porselen uygulanarak restorasyon bitirildi. Sabit restorasyonun oklüzyonu kontrol edilerek mumlu kapanış elde edildi. Sabit kısmın üzerinden elastomerik ölçü maddesi ile yumuşak doku sınıllarını da içeren ölçü alındı. İçinde sabit komponentin yer aldığı ölçüden elde edilen ana modeller üzerinde hareketli komponent, sabit kısımla uyumlu olacak şekilde laboratuvarda hazırlandı (Şekil $5)$.
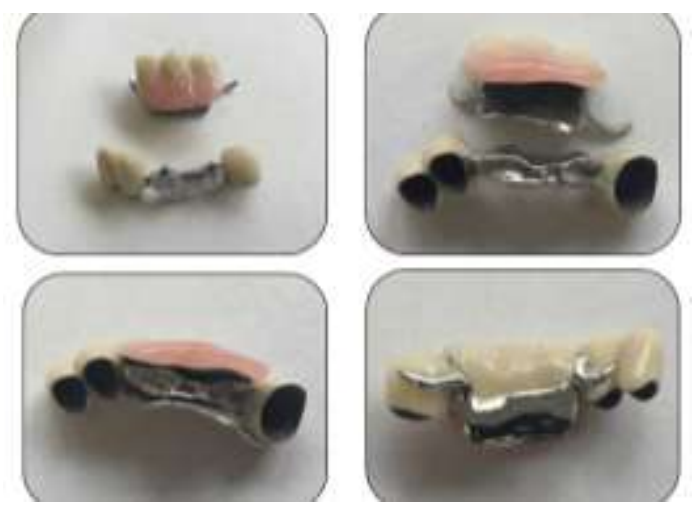

Şekil 5. Krom-kobalt bardan oluşan sabit kısım ve sabit kısma uyumlu hazırlanan hareketli parça

Hasta ağzında fonksiyon, fonasyon ve estetik açıdan kontrol edilen protezin bitim işlemi gerçekleştirildi. Sabit restorasyon cam iyonomer siman (KETAC CEM GLASS IONOMER; 3M Espe, Minnesota, USA) ile yapışııııldı (Şekil 6,7). Maxiller bölgede dişsiz boşluklar hareketli parsiyel protez ile tedavi edildi (Şekil 8). 12 ay süren takip boyunca klinik olarak yapılan incelemelerde hastanın "Sabit-Hareketli Protez"'den estetik, fonksiyon ve fonasyon bakımından memnun olduğu gözlemlendi (Şekil 9).

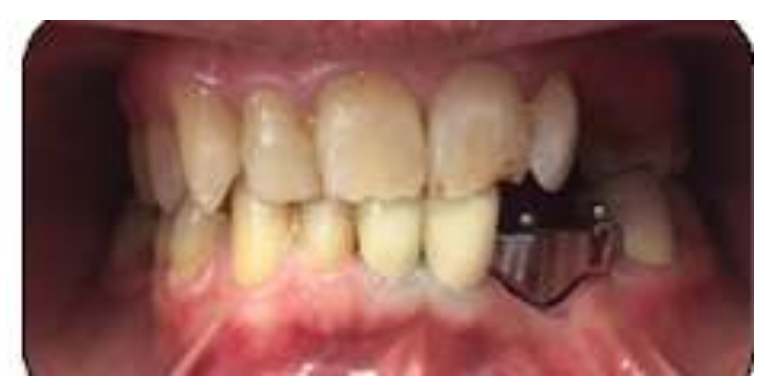

Şekil 6. Simante edilen sabit komponent

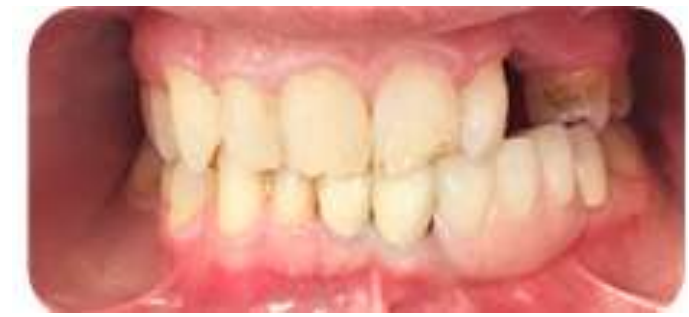

Şekil 7. Sabit kısım üzerinde hareketli kısmın bitim işlemlerinin gerçekleştirilmesi

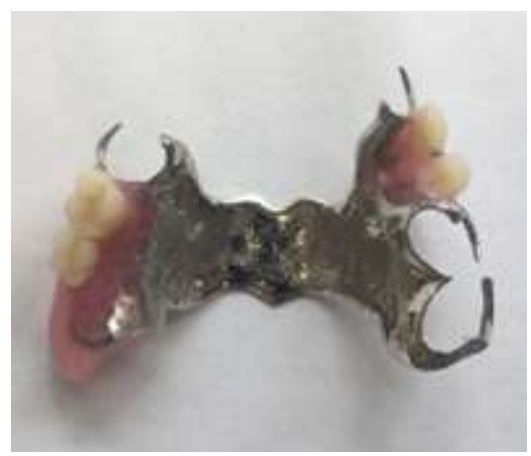

Şekil 8. Üst çene dişsiz boşluklar için hazırlanan hareketli parsiyel protez

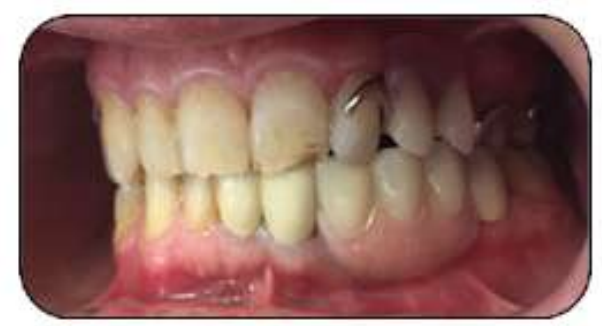

Şekil 9. İntraoral bitim fotoğrafı

\section{VAKA 2}

Atatürk Üniversitesi Diş Hekimliği Fakültesi Protetik Diş tedavisi kliniğine başvuran 27 yaşındaki erkek hastanın mevcut kısmi dişsizliğinin tedavisi için klinik ve radyolojik muayenesi yapıldı (Şekil 10). Hastadan gerekli prosedürlerin ayrıntılı anlatıldığı, çalışmada yer almayı kabul ettiği gönüllü onam formu alındı. 


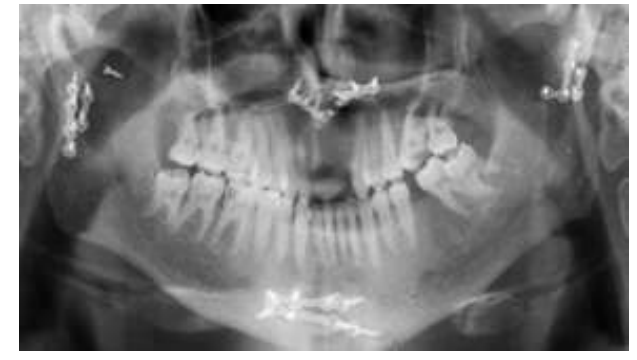

Şekil 10. Hastanın panoramik radyografisi

Alınan anamnezde hastanın 2 sene önce trafik kazası geçirdiği ve bu kaza sonucu maksillada oluşan kırıkların kazadan 10 gün sonra miniplaklarla fikse edildiği öğrenildi. Sağ üst santral kökün çekimi yapıldı. Hastanın klinik muayenesinde maksillada daralma sonucu bilateral posterior çapraz kapanış ve maksilla anterior bölgede dikey ve yatay sert ve yumuşak doku kayıpları gözlendi (Şekil 11).

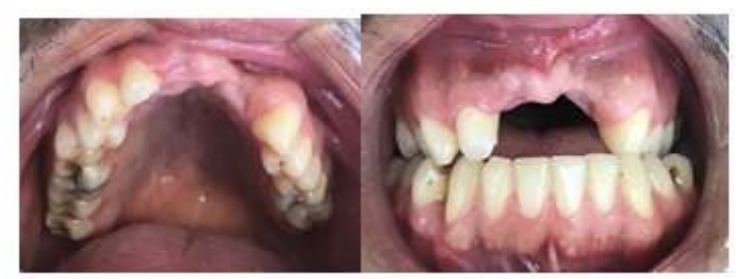

Şekil 11. İşlem öncesi hastanın intraoral fotoğrafları

Hasta, posterior çapraz kapanışından şikayetçi olmadığını sadece maksiller anterior bölgedeki dişsiz alandan estetik yönden şikayetçi olduğunu bildirdi. Maksiller anterior bölgedeki dikey ve yatay doku kayıpII boşluğa "Andrews Köprü Sistemi" yapılmasına karar verildi. Sağ üst lateral, kanin ve birinci küçük azı dişleri ile birlikte sol üst kanin ve birinci küçük azı dişleri Andrews Köprü Sisteminin sabit komponentinin destek dişleri olarak belirlenerek preparasyonları gerçekleştirildi.

Elastomerik ölçü maddesi (ELITE HD PUTTY; Zhermack, Rovigo, Italy) kullanılarak ölçü alındı. Sabit restorasyonun yapılması için laboratuvarda alçı model elde edildi. Sabit restorasyonun alt yapısı "Dolder Bar Sistemi" referans alınarak dizayn edildi. Krom kobalt alaşım sabit alt yapının dökümünde kullanıldı (Şekil 12).

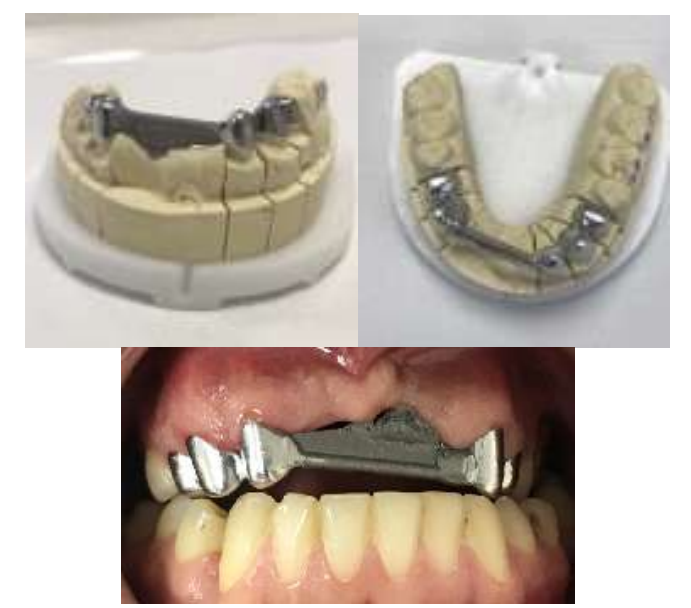

Şekil 12. Metal altyapının model üzerinde ve intraoral görünümü

Sabit restorasyonun oklüzyonu kontrol edildikten sonra kapanış silikonu (OCCLUFAST ROCK Zhermack, Rovigo, Italy) ile kapanış kaydı elde edildi. Sabit kısmın üzerinden elastomerik ölçü maddesi ile yumuşak doku sınırlarını da içeren ölçü alındı. İçinde sabit komponentin yer aldığı ölçüden elde edilen ana model üzerine hareketli komponent, sabit kısımla uyumlu olacak şekilde laboratuvarda hazırlandı (Şekil 13). Hareketli komponentin hazırlanmasında polimetilmetakrilat esaslı sıcak akrilik malzemesi(IQ-15 SICAK AKRİLiK; Imicryl, Konya, Türkiye) ve akrilik dişler (PRIMADENT; Imicryl, Konya, Türkiye) kullanıldı.

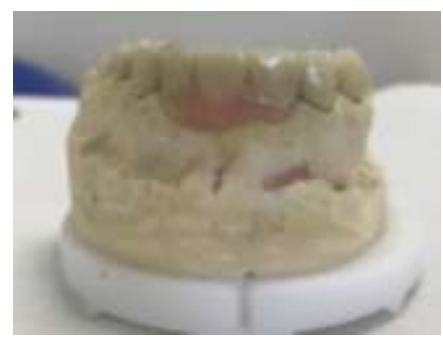

Şekil 13. Feldspatik porselen uygulanan protezin model üzerinde görünümü

Sabit restorasyon cam iyonomer siman (KETAC CEM GLASS IONOMER; 3M Espe, Minnesota, USA) ile simante edildi. 12 ay süren takip boyunca klinik olarak yapılan incelemelerde hastanın "Sabit-Hareketli Dental Protez'"den estetik, fonksiyon ve fonasyon bakımından memnun olduğu gözlemlendi (Şekil 14). 


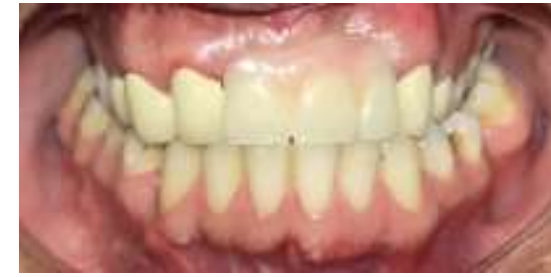

Şekil 14. İntraoral bitim fotoğrafı

\section{TARTIŞMA}

Çoklu diş eksikliklerinde çoğunlukla hareketli parsiyel protez tedavisi uygulanmaktadır. Zamanla dişsiz bölgelerde rezorbsiyona bağlı olarak, alveol kemiğin boyutlarında azalma meydana gelmektedir. Seibert 'e göre dişsiz alanlardaki kret defektleri üç sınıfa ayrılmaktadır. Sınıf I defekt, apikal-koronal yönde normal yükseklik, bukko-lingual yönde doku kaybını, sınıf II defekt, bukko-lingual yönde normal genişlik, apikal-koronal yönde doku kaybını, Sınıf III defekt ise hem apikal-koronal, hem de bukko-lingual yönde doku kaybını belirtir. Özellikle yetersiz yüksekliğe ve genişliğe sahip Siebert's Sınıf III kretlerde hareketli protez kullanılarak tedavi edilebilir. ${ }^{8}$ Ancak hareketli parsiyel protez hasta için konforsuz olmakla beraber, yeterli tutuculuğa ve estetiğe sahip olmayabilir. Bu sebeple hastalar çoğunlukla sabit protez istemektedirler. Ancak uzun dişsiz boşluklar ve geniş doku kayıpları, sabit protezin uzun dönem prognozunu olumsuz yönde etkilemektedir. Bu durumlarda, geleneksel sabit dental protezlerin yapılması uygun değildir çünkü Andrews köprü sistemiyle kıyaslandığında birçok kozmetik, hijyenik ve işlevsel açıdan dezavantaj oluşturur. ${ }^{9}$ Sabit dental protezler böyle durumlarda kullanıldığında karanlık alanlar gibi, hem estetik yönden iyi görünmeyen hem de gıda birikimi için potansiyel temizlenemeyen alanlar oluşturacaktır. Diğer taraftan, Andrews köprü, akrilik hareketli kısımla estetik, fonasyon ve hasta tarafından rahat temizlenebilmesi gibi birçok avantaja sahiptir. ${ }^{10}$ Pek çok yazar kaybolan dikey kret hacmini yeniden kazanmak için interpozisyon greftleri ve onlay greftler gibi yumuşak doku cerrahilerini savunmuş olsa da ${ }^{11,12}$ bu prosedürlerin sadece birkaçında, kret yüksekliği herhangi bir öngörülebilirlikle artabilir. ${ }^{13} \mathrm{Bu}$ duruma çözüm olarak geliştirilen sabit-hareketli protezde, belirlenen destek dişler için hazırlanan metal porselen kuronlarla önceden hazırlanmış bar ile birleştirildikten sonra ağıza kalıcı olarak simante edilir ve hareketli kısım akrilikten yapılarak sabit kısıma tutunur. ${ }^{12}$
Akay ve ark. ${ }^{15}$ yaptıkları çalışmada yarık damak ve dudak hastalarının tedavisinde tek başına sabit veya tek başına hareketli protez ile istenilen düzeyde kalıcı restorasyon yapmanın mümkün olmadığını, tercihen sabit hareketli protez kombinasyonlarının yapılmasının uygun olduğunu belirtmişlerdir. Shahroom ve ark. ${ }^{16}$ Siebert Sınıf I için yumuşak doku augmentasyonu, Sınıf II için interpozisyonel greftli alveolar osteotomi, Sınıf III defektte Andrews köprü önermiştir. Sajjad $^{9}$ yaptığı çalışmada kişisel döküm yivli bar yaparak geleneksel sabit dental protezlere ve yumuşak doku cerrahisi gerektirecek Sınıf II ve Sınıf III defektlere basit, ekonomik ve kullanıc dostu bir alternatif olarak önermiştir. Estetik isteğin daha fazla olduğu ve hareketli protezin ana bağlayıcılarının konforundan memnun kalmayan dudak damak yarıkı hastalarda hassas tutuculu ve Andrews köprü tarzı barlı protezler de güzel alternatif oluşturmaktadır. ${ }^{17}$ Balakrishnan ve $\operatorname{ark}^{18}$ konvansiyonel hareketli protezlerle kıyaslandığında sabit hareketli protezin tamamen diş kaynaklı olması ve okluzal kuvvetlerin destek dişlerin uzun aksına daha dik kuvvetlerle gelmesinden dolayı daha stabil olduğunu savunmaktadır. Rathe ve $\operatorname{ark}^{19}$ yaptıkları çalışmada mandibular fraktür bulunan Siebert Sınıf III hastada Andrews köprü sisteminin içine mıknatıs yerleştirerek, oluşan manyetik çekim ile tutuculuğun arttığını ortaya koymuştur. Tambe ve ark ${ }^{20}$ yaptıkları çalışmada Andrews köprü sisteminin çıkarılabilir parsiyel proteze göre retansiyon, stabilite, hasta konforu, temizlenebilme, fonetik, estetik ve ekonomik açıdan daha avantajlı olduğunu belirtmiş olup, maksiler anterior bölgedeki dikey doku defektli vakalarında bar bağlantılı Andrews köprü sistemi kullanmışlardır. Manoaharan ve ark. ${ }^{21}$ yaptıkları çalışmada implant destekli sabit restorasyonların da alternatif bir tedavi seçeneği olabileceğini belirtmiştir. Fakat kemik defekti veya uzun süre dişsiz kalan bölgelerdeki kemik rezorpsiyonlarından dolayı kalan kemik varlığı ve bunun sonucunda artacak olan kuron oranı bu seçeneği sınırlandırmıştır.

Literatürde başarısızıklarla ilgili sınırlı bilgi bulunmaktadır. Başarısızlıklar esas olarak yetersiz lehimlemeden kaynaklanmakta olup bu da tutucuların tek bir dökümde bara birleştirilmesiyle önlenebilmektedir. ${ }^{22}$

\section{SONUÇ}

Andrews köprü sistemi; minimal yer kaplaması, geniş doku kaybı nedeniyle oluşan boşlukların uygun şekilde rehabilite edilebilmesi, destek dişlerin bar 
AYDIN, YANIKOĞLU, ÖZMEN

sitemi ile splintlenmesi ve hareketli kısmın hijyen bakımından kolaylıkla çıkarılıp yıkanabilmesi bakımından avantajıdır. Bunun yanında maliyet ve klinik seans sayısının zaman alması gibi dezavantajlara sahiptir.

NOT: Calışmada herhangi bir yazar, kurum ya da kurulus ile çıkar çatışması içerisinde bulunmamaktadır. Makale daha önce hiçbir yerde yayınlanmamış ve yayınlanmak üzere işlem görmemektedir

\section{KAYNAKLAR}

1. Carr AB, Brown DT. McCracken's Removable Partial Prosthodontics. 12 ed .St Louis;Elsevier Mosby; 2011. p. 1.

2. Andrew J. A., \& Bigg W. F. Andrew's bar and sleeve retained bridge: a clinical case report. Dent Today 1999; 18:94-6.

3. Everhart R. J., \& Cavazos E. Evaluation of a fixed removable partial denture: Andrews Bridge System. J Prosthet Dent 1983; 50:180-184.

4.Maji S., Patro T. K., Dhal A., \& Garhnayak L. Restorıng Teeth And Large TIssue Defect Usıng Andrew's Brıdge:A Case Report. IJSR 2018; 7.

5. Korkmaz T., \& Yılmaz C. Maksiller Defektin Andrews Köprü Sistemiyle Restorasyonu :Vaka Raporu. GÜ Diş Hek Fak Derg 2005; 22: 37-39.

6. Cheatham J. L., Newland J. R., Radentz W. H., \& O'Brien R. The 'fixed'removable partial denture: report of case. J Am Dent Assoc 1984; 109:57-59.

7. Angadi P. B., Aras M., Williams C., Nagaral S., \& Angadi P. Precision attachments; applications and limitations. J Evol Med Dent Sci 2012; 1:1113-21.

8. Shillingburg HT, Hobo $S$, Whitsett LD, Jacobi R, Brackett SE. Fundementals of Fixed Prosthodontics. 3th edition, London, U.K: Quintessence Publishing Co., Inc., 1997

9. Sajjad A. Andrews bridge revisited: A new custom cast ribbed bar and sleeve design fixed removable partial denture. J. Dental Allied Sci 2017; 6:44.

10. Andrews J. A., \& Biggs W. F. The Andrews barand-sleeve-retained bridge: a clinical report. Dent today 1999; 18:94-6.

11. Seibert J. S. Reconstruction of deformed, partially edentulous ridges, using full thickness onlay grafts, Part I. Technique and wound healing. Compend Contin Educ Dent 1983; 4: 437-53.

12. McHenry K. R., Smutko G. E., \& McMullen J. A. Restructuring the topography of the mandibular ridge with gingival autografts. J Am Dent Assoc 1982; 104:478.
13. Rosenstiel SF, Land MF, Fujimoto J. History taking and clinical examination. In: Contemporary Fixed Prosthodontics. $3^{\text {rd }}$ ed. St. Louis: Mosby; 2001. p. 514.

14. Walid S., Bone anchored Andrew's bar system a prosthetic alternative. Cairo Dent. J., 1995. 11:115

15. Akay C., Karakış D., \& Yaluğ S. Dudak Damak Yarıklı Hastada Estetik Ve Fonksiyonel Protetik Rehabilitasyon. Atatürk Ün iv Diş Hek Fak Derg 2014; 24.

16.Shahroom N. S. B., \& Jain A. R. Prevalence of (alveolar ridge defect) using Seibert's classification in fixed partial denture patient. Drug Invent Today 2018; 10:756

17. Çakan U., Güncü B., Germeç D., \& Aslan Y. Yarık damak dudak hastalarında protetik rehabilitasyon. Yeditepe klinik 2006; 2:11-6.

18. Balakrishnan D., Ahmad M., Albinali A., Areashi A., \& Naim H. An Evidence Based Restoration of Esthetically Challenged Maxillary Anterior Arch with Andrews Bridge System:A Case Report with 5 Years of Follow Up. Dentistry 2016; 6:2161-1122.

19. Rathee M., Sikka N., Jindal S., \& Kaushik A. Prosthetic rehabilitation of severe Siebert's Class III defect with modified Andrews bridge system. Contemp Clin Dent 2015; 6:114.

20. Tambe A., Patil SB., Bhat S., \& Badadare MM. Andrew's bridge system: an aesthetic and functional option for rehabilitation of compromised maxillary anterior dentition. BMJ Case Rep 2014; 3.

21. Manoaharan PS., Mohamed Ali SA., Selvarangam S., Balaji J., \& Ibthigar M. A Forgotten Technique for Replacement of Maxillary Anteriors and an associated Bony Defect: A Case Report J Int Oral Health 2015; 7:59-61

22. Janani T. Rehabilitation of Sieberts Class III Defect Using Fixed Removable Prosthesis (Andrew's Bridge):A Case Report. J Pharm Sci \& Res 2016; 8:1045.
Yazışma Adresi
Prof. Dr. Nuran YANIKOĞLU
Atatürk Üniversitesi
Diş Hekimliği Fakültesi
Protetik Diş Tedavisi AD, Erzurum
E-mail: nyanikoglu@yahoo.com 